\title{
A boundary-spanning organization for transdisciplinary science on land stewardship: The Stewardship Network
}

\author{
A. Paige Fischer ${ }^{1}$
}

\begin{abstract}
Although people and organizations in the Great Lakes region, USA take seriously their role as stewards of natural resources, many lack capacity to fulfill that role in a meaningful way. Stepping into that gap, The Stewardship Network (TSN) envisions "a world of empowered, connected communities caring for land and water, now and forever," and fulfills that vision through its mission to "connect, equip, and mobilize people and organizations to care for land and water in their communities." TSN uses a scalable model of linked local and regional capacity building, science communication, civic engagement, and on-the-ground stewardship activities to achieve these goals. The model engages local and regional groups in an ongoing process of learning around conservation and restoration that improves social and ecological knowledge. I share the story of TSN to demonstrate how transdisciplinary science can take hold locally and expand regionally to bring people from diverse disciplines and functional roles together to solve common problems. I demonstrate how researchers and practitioners can collaborate to create enduring mechanisms of social and ecological change.
\end{abstract}

Key Words: Great Lakes; restoration; social learning; stewardship

\section{INTRODUCTION}

The Great Lakes region of North America is home to globally significant natural lands and waters. Together, the five lakes, i.e., Superior, Michigan, Huron, Erie, and Ontario, are the largest system of fresh surface water on Earth, containing approximately $18 \%$ of the world's fresh water supply. As a result of the unique glacial history of the region and the distinct underlying geology, Great Lakes habitats are extremely diverse. Lakes, rivers, forests, prairies, alvars, beaches, dunes, and coastal bluffs provide homes to numerous fish such as walleye, whitefish, trout, and lake sturgeon, and wildlife, including the gray wolf, Canada lynx, and many migratory birds. The southern portion of the basin is also home to one-tenth of the population of the United States and, thus, is facing increasing pressure from land use and development. Concerns about climate change, invasive species, and water quality also cut across conservation and stewardship interests in the region. As a place where the farmbelt meets the rustbelt, the Great Lakes Region is both a hallmark and a beacon for some of today's most compelling land-use and conservation issues.

While the Great Lakes Region's people and organizations take seriously their role as stewards of these natural resources, many lack capacity to fulfill that role in a meaningful way. Stepping into that gap, The Stewardship Network (TSN) envisions "a world of empowered, connected communities caring for land and water, now and forever." TSN fulfills its vision through a mission "to connect, equip, and mobilize people and organizations to care for land and water in their communities" (https://www. stewardshipnetwork.org/about-us). TSN uses a scalable model of linked local and regional capacity building, science communication, civic engagement, and on-the-ground stewardship activities to achieve these goals. The model engages local and regional groups in an ongoing process of learning around conservation and restoration that improves social and ecological knowledge. Here, I share the story of TSN to demonstrate how transdisciplinary science can take hold locally and expand regionally to bring people from diverse disciplines and functional roles together to solve common problems. I demonstrate how researchers and practitioners can collaborate to create enduring mechanisms of social and ecological change.

\section{LOCAL ROOTS OF THE STEWARDSHIP NETWORK}

TSN formed in 1998 in response to growing recognition of the limitations of parcel-by-parcel land conservation for strategic, long-term stewardship in the Huron River watershed in southeast Michigan. Three organizations, i.e., the City of Ann Arbor, Michigan, the University of Michigan (specifically, the School of Natural Resources and Environment, Nichols Arboretum, and Matthaei Botanical Gardens), and the Huron River Watershed Council, came together to create a network of stewardship organizations to coordinate efforts to protect biodiversity, ecosystem integrity, and open space in the local watershed. Lisa Brush, a graduate of the School of Natural Resources and Environment, took the helm of TSN because she recognized the transformative power of bringing people together to create real change. "The problems we were facing then, that we're still facing today, were on a bigger scale than any one organization could fix," says Brush. "All of these lands, all of these issues, are connected. And so we need to bring together all of the people and groups working on water health, the invasive plants, and the other ecological issues to care for nature on a systemic level."

TSN's initial goal was to build a community of conservation practitioners to coordinate conservation in the Huron River watershed to improve the efficiency and quality of their work. The organization's first undertaking was to facilitate a stakeholder process to decide what to do with the local school-district-owned forest lands that had succumbed to the invasive gypsy moth. Although the school district had no lack of stewardship-minded volunteers, the district and its volunteers were not equipped to handle issues that require active management such as the standing dead oak trees and invasive species in the woods. TSN brought together representatives from local land conservancies, watershed councils, municipal parks departments, scientific experts, local school volunteers, property owners, and citizens in a deliberative process. The result was a decision to leave the dead trees standing for wildlife habitat rather than remove them to make way for another, perhaps more aesthetically pleasing, land use. Through this process, stakeholders hungry for decision-making frameworks became convinced that a more formal model to empower local groups to make stewardship decisions was needed. 
Fig. 1. The Stewardship Network's current clusters (colored polygons) and emerging clusters (circles) in the Great Lakes region.

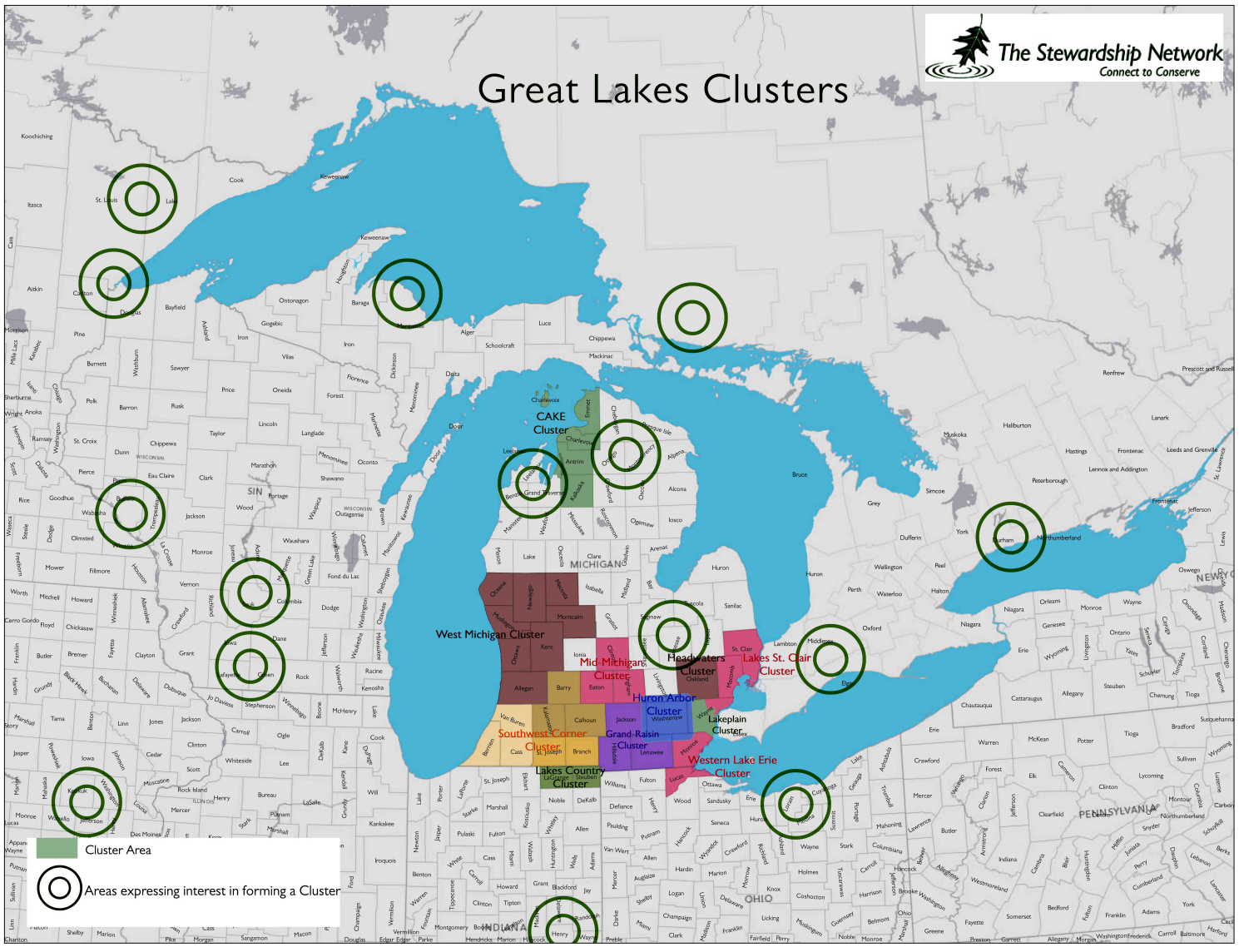

As TSN continued to work with stakeholders to make decisions and plan stewardship activities, it helped to gather a set of local practitioners who felt validated, credible, and empowered to engage in stewardship activities. By organizing workshops, training, and tours of restoration and invasive species management sites, TSN's process created opportunities for stakeholders to learn from each other. The ambitions of the practitioners grew, and TSN took on a more expansive role. Inspired by the success of the regional alliance Chicago Wilderness (Moskovits et al. 2004, McCance 2011), TSN facilitated a process in 1998 to identify restoration priorities for the Huron River watershed that entailed bringing experts together to characterize the historic landscape, organizing restoration workshops and tours of restoration areas, and convening the group to discuss challenges and consult experts on restoration techniques. Robert Grese, a professor at the School of Natural Resources and Environment; Paul Rentschler, director of the Huron River Watershed Council; and David Borneman, director of the City of Ann Arbor's Natural Areas Program, were instrumental during the early formation of TSN and the articulation and implementation of the local stewardship strategy. Borneman had followed the progress of Chicago Wilderness closely and sensed that conditions in the growing TSN were ripe for a collective restoration effort around Ann Arbor. Rentschler brought experience in leading a conservation nonprofit at a watershed scale and working with an assortment of public agencies in the region. Grese, a visionary landscape architect, shared his passion and skill for ecological restoration, often demonstrating the use of prescribed fire as a management tool on University grounds and even in his own front yard. Soon, the group decided on a set of restoration priorities and restoration techniques, including reintroducing natural fire as a disturbance process in the woodlands and prairies in the Huron River watershed.

Hearing of the success of the Huron River watershed process, conservation stakeholders in other geographic areas reached out to TSN. In 2001, the Raisin Valley Land Trust and a group of rural residents in the Raisin River watershed in south-central Michigan contacted TSN for help increasing their capacity to manage land actively to improve ecological quality. TSN agreed to assist the group with on-the-ground conservation action and planning. TSN first worked with the group to help it educate its members about local conservation issues and how to care for local land and water resources. The Raisin Cluster decided it wanted to restore the local ecosystems and use prescribed fire as a restoration tool. Through workshops, training activities, and online networking to share ideas, information, skills, and resources, TSN helped local landowners develop the skills to apply 
this technique for stewarding habitat and plant and animal species on their properties. Soon after, a group of conservationists in the Six Rivers watershed on the outskirts of Detroit contacted TSN to help develop a strategy for conserving remnant habitat and open space in the rapidly urbanizing landscape of southeast Michigan. With its strategic model honed, TSN became an independent, federally recognized nonprofit organization in 2004. Shortly thereafter, it began experimenting with different funding models to increase local capacity for stewardship among several groups in southwest Michigan. Realizing that costs and coordination of stewardship were the overarching barriers for these groups, TSN helped them collectively hire labor, rent equipment, and secure expertise, increasing the economy of scale of the on-the-ground stewardship work. TSN then turned its attention to a much broader geographic area: the wider Great Lakes Region. Since then, TSN has helped launch a total of 10 clusters around the states of Michigan, Ohio, and Indiana, and is in the process of facilitating the emergence of five new clusters in Wisconsin, Indiana, and Minnesota, as well as a new stewardship network in the New England area (Fig. 1). TSN is also in discussions about 17 other possible clusters in the United States and abroad.

\section{A BOUNDARY-SPANNING ORGANIZATION}

TSN is best described as a boundary organization (Guston 2001, O'Mahony and Bechky 2008). The group brings transdisciplinary science on the interactions of ecology and society into practice in the field of community-based collaborative conservation. At the request of local community members and organizations, TSN facilitates planning processes that bring diverse stakeholders together to develop shared understanding of ecological problems, build trust, and collaboratively pursue common goals. These processes engage dozens of private landowners, conservation groups, community groups, experts from ecological and social science disciplines, and municipal, state, federal, and tribal natural resource agencies. TSN begins each process with an Exploring the Possibilities Workshop. TSN starts the workshops with conversations about the following questions: What are the ecological issues of concern to this group of people? What are the barriers to addressing those concerns? What are the opportunities? What is the geographic area this group of people is concerned about? Who is not at the table for this conversation? Who else should be at the table? (Fig. 2). If the group still wants to move forward after answering these questions, TSN will continue to facilitate the strategic planning process. TSN follows up on the planning processes by helping establish and support socially and ecologically coherent stewardship institutions, called clusters, to implement the strategies they develop. Based on the concept of eco-civic regions (Brunckhorst et al. 2006), TSN's clusters serve as enduring social structures through which communities collectively plan and implement stewardship activities that address salient local ecological concerns in culturally appropriate ways.

TSN supports the clusters with ongoing education, capacitybuilding programs, and networking services, and by connecting clusters with conservation funding, equipment, and labor. Each year, TSN convenes a cluster summit that brings together the coordinators of each cluster for peer learning exercises; discussions of challenges, opportunities, and strategies; and training in facilitation, leadership, capacity building, and stewardship and conservation. In addition, an annual conference brings scientists and practitioners together to share the latest thinking on habitat restoration. The Science, Practice and Art of Restoring Native Ecosystem Conference started out as a symposium for practitioners to learn about the applicability of emerging research findings to on-the-ground conservation. The meeting provided a safe place for researchers, who were not used to being in the position of having research findings directly translated into practice, discuss and interpret preliminary results with practitioners. As demand for research grew and trust developed between stewardship-oriented researchers and practitioners, the conference became an annual public event, now attracting hundreds of presenters. Throughout the rest of the year, webcasts connect hundreds of scientists and practitioners each month to share information on a wide range of topics, including wildlife management, native and invasive plant identification, biological control methods, habitat restoration, volunteer programs, and $\mathrm{K}-12$ environmental education. Closer to home, informal monthly gatherings bring people together with guest practitioners and researchers who share experiences and expertise on a topical issue. TSN began convening this group in 1998 on the second Tuesday morning of each month at a local eatery. Now formally known as the Stewards Circle, the gathering continues with minimal TSN involvement, attracting landowners and conservationists in Ann Arbor and well beyond.

Fig. 2. Word diagrams of salient themes in the discussion about stewardship barriers (A) and opportunities (B) in the Exploring the Possibilities Workshop for the emerging cluster in Ely, Minnesota.

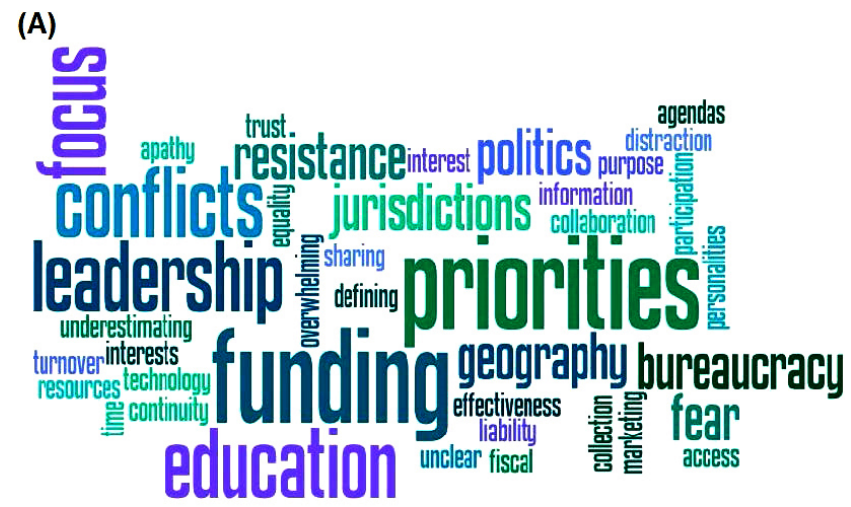

(B)

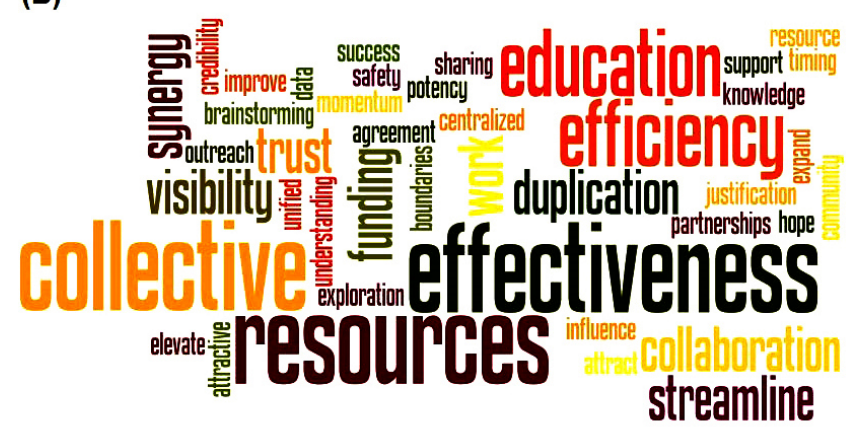


Across the Great Lakes Region, an ongoing series of $\sim 100$ workshops per year brings scientists and practitioners together to compare factors in the success of stewardship activities and to develop new techniques. For example, TSN organized a prescribed fire workshop for private landowners in the West Michigan Cluster who were interested in using fire to restore lands to pre-1800 conditions yet lacked experience and confidence. TSN brought prescribed fire experts together with representatives of natural resource agencies, private landowners, volunteers, and other stewardship professionals to learn about and practice prescribed fire on the lands of cluster members. These capacity building efforts prepared a set of landowners to take advantage of Department of Natural Resources cost-share funds for active restoration management. TSN also partnered with Michigan State University (MSU) to organize a set of field days to bring researchers and practitioners from across the state of Michigan together to learn about restoring rare ecosystems found on MSU's MacCready Reserve. Held over the course of several years, the field days created opportunities for researchers and practitioners to share and learn from each others' experiences restoring prairie fen and oak savanna ecosystems. Doug Landis, a professor at MSU and former TSN board president, recalls how such activities created social conditions for transdisciplinary science. "As we were walking to view the restoration research that MSU had been doing, someone asked about an invasive plant along the trail. Knowing that one of the tour participants was an experienced hand with that particular species, the MSU researcher leading the tour quickly turned and asked that individual to explain to the group how they would handle this situation. Through that interaction, the practitioner's experiential knowledge was recognized and valued as highly as the scientist's. This is what can happen when you bring researchers and practitioners together," says Landis. Local on-the-ground stewardship activities such as these bring ecological and social scientists and practitioners together to test techniques and innovate restoration practices, generating new knowledge that they can share back through the conferences.

\section{A MODEL OF STEWARDSHIP LEARNING}

TSN's approach counters a long tradition of science communication in which researchers generate disciplinary scientific knowledge and transfer it to practitioners, a unidirectional model that has been criticized for being unsuitable for addressing complex problems (Roux et al. 2006). In the preferred alternative, researchers and practitioners generate new knowledge collectively (Holling 1978, Rogers 1983, Walters 1986, 1998, Roux et al. 2006). This bidirectional model of knowledge generation draws from organizational learning theory, which postulates that learning is a social process in which individuals acquire, create, and transfer knowledge, and develop new collective approaches based on this new knowledge (Argyris and Schon 1978, Garvin 1993, Nonaka 1994).

Social learning theory distinguishes between two types of knowledge: tacit knowledge, which is knowledge gained through observation and transferred through shared experience; and explicit knowledge, which is codified knowledge transmitted in formal, systematic language (Nonaka 1994). The process of knowledge creation involves communication of tacit knowledge within communities of practice, or socialization; conversion of tacit knowledge to explicit knowledge, or externalization; combination of different bodies of explicit knowledge; and internalization of new explicit knowledge back into tacit knowledge through practice (Nonaka 1994).

TSN implements this social learning model by facilitating interactions between practitioners and researchers at the outset of defining problems; in the design, implementation, and interpretation of scientific research; and when practitioners test scientific principles in practical application. Local on-the-ground stewardship activities create opportunities for ecological and social scientists and practitioners to develop and communicate tacit knowledge about restoration. The annual conferences and monthly webcasts encourage scientists and practitioners to convert their tacit knowledge into explicit knowledge that can be shared with others, and they provide opportunities for ecological and social scientists and practitioners to combine their knowledge. Meetings within the conferences, the ongoing workshop series, and field days bring scientists and practitioners together to combine their knowledge. Local on-the-ground stewardship activities in turn create opportunities for internalizing the new explicit knowledge back into tacit knowledge through practice. By facilitating communication, joint problem solving, and collaboration among ecological and social scientists and practitioners, TSN creates a rare cycle of opportunity for co-generation and application of transdisciplinary scientific knowledge, also called stewardship learning (Fig. 3). TSN's Iron Creek Properties (ICP), a project of the recently expanded Grand-Raisin Cluster, brings local landowners together with restoration ecologists to control invasive plants and provides an example of transdisciplinary science in action (Fig. 4).

Fig. 3. The Stewardship Network's stewardship learning model based on Nonaka (1994).

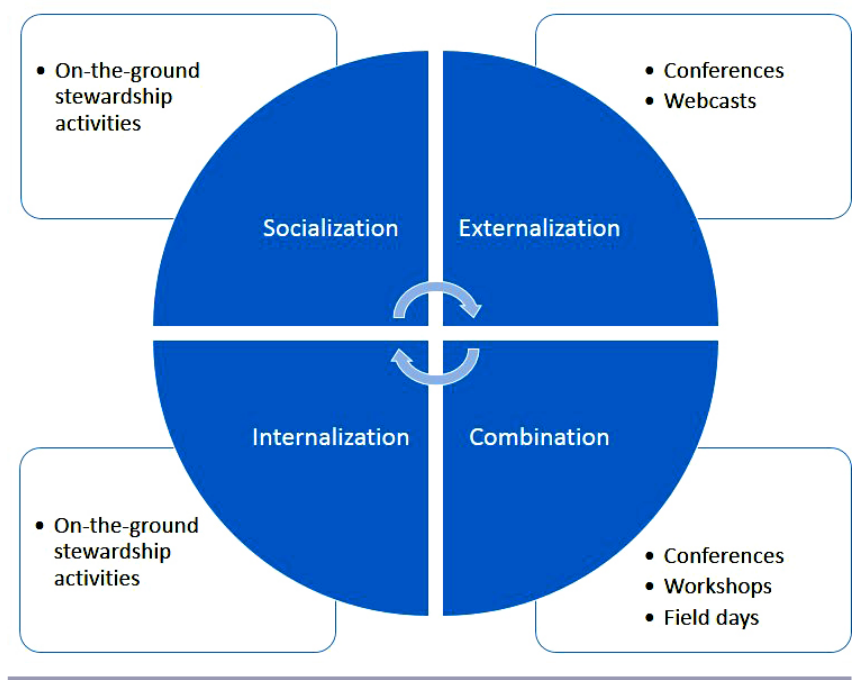

\section{SUCCESSES IN BRINGING TRANSDISCIPLINARY SCIENCE OF SOCIAL-ECOLOGICAL INTERACTIONS INTO PRACTICE}

TSN's cross-disciplinary multiscalar approach has enabled the organization to cross divides between ecology and society, research and practice, and knowledge and action that have hindered stewardship in the past. TSN's clusters now engage 
ecological and social science in the practice of stewardship across the Lake States and northeastern United States. Equipped with the latest scientific ecological knowledge to complement their own place-based experiential knowledge, 10,000 practitioners within these clusters have enhanced $>4047 \mathrm{~km}^{2}$ of land by removing invasive species, improving water quality, and restoring wildlife habitat. For example, for the past eight years, TSN has sponsored a competition among the clusters called the Garlic Mustard Challenge (Fig. 5). Clusters vie for the prize by reporting the weight of invasive garlic mustard they remove and the number of sites they maintain as garlic-mustard-free. In Michigan alone, TSN's clusters annually remove $113,400 \mathrm{~kg}$ of garlic mustard on average, and the number of garlic mustard free sites continues to rise.

Fig. 4. The Iron Creek Properties project of The Stewardship Network.

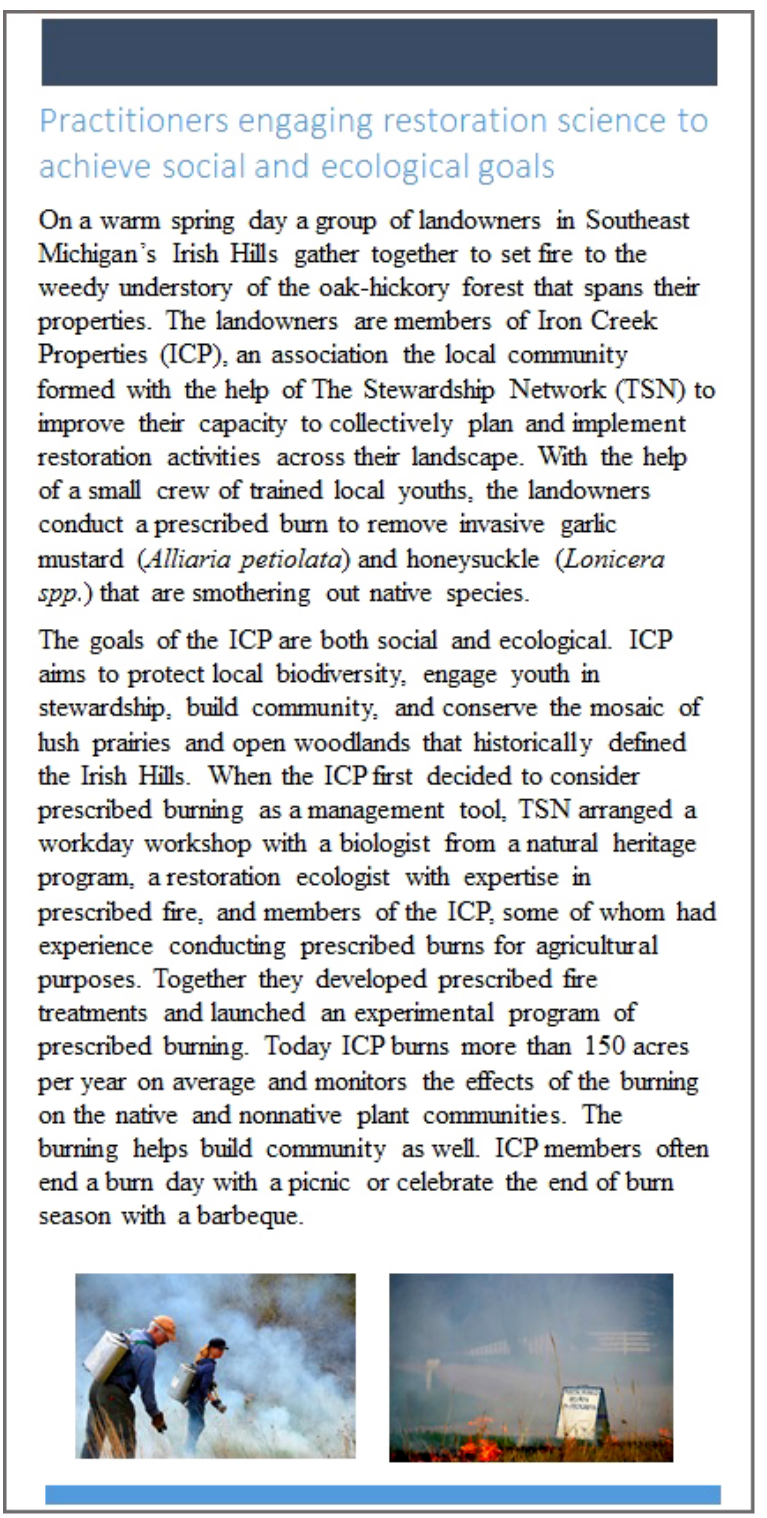

The efforts of the individual clusters have resulted in measurable environmental outcomes. For example, two years after the launch of TSN's West Michigan Cluster, the area of land managed for ecological values in the area increased $42 \%$, the number of volunteer workdays increased $82 \%$, and the number of volunteer hours for local stewardship increased $63 \%$. In the four years after the launch of the Mid-Michigan cluster, volunteers and staff logged $334 \mathrm{~h}$ treating invasive plant species, including Phragmites australis and Japanese knotweed (Fallopia japonica) on 89 sites. Building on years of restoration success, the Grand-Raisin Cluster, with help from TSN, was selected to participate in Cooling the Hotspots: Great Lakes Restoration Initiative, a project that provides incentives to the owners of agricultural lands to reduce the amount of nutrients that might be leaving their lands. This project will help implement the River Raisin Watershed Management Plan and several Lake Erie plans, ultimately reducing nutrient and sediment loads from agricultural areas in the watershed. The project pays for performance: a recognized innovative approach to achieving water quality targets while simultaneously supporting productive use of the land. The project aims to improve the drinking water supply and reduce the prevalence of harmful algal blooms in Lake Erie by rewarding farmers for adopting best management practices. Cluster farmers aim to reduce their contributions to phosphorus, nitrogen, and sediment pollution. In recognition of these and other achievements, TSN received the Natural Areas Association's highest honor, the Carl N. Becker Stewardship Award, in 2013 for revolutionizing the scope of and community involvement in the stewardship of natural areas conservation by developing and supporting collaborative communities focused on conservation.

Fig. 5. The Garlic Mustard Challenge supports crossgeneration learning.

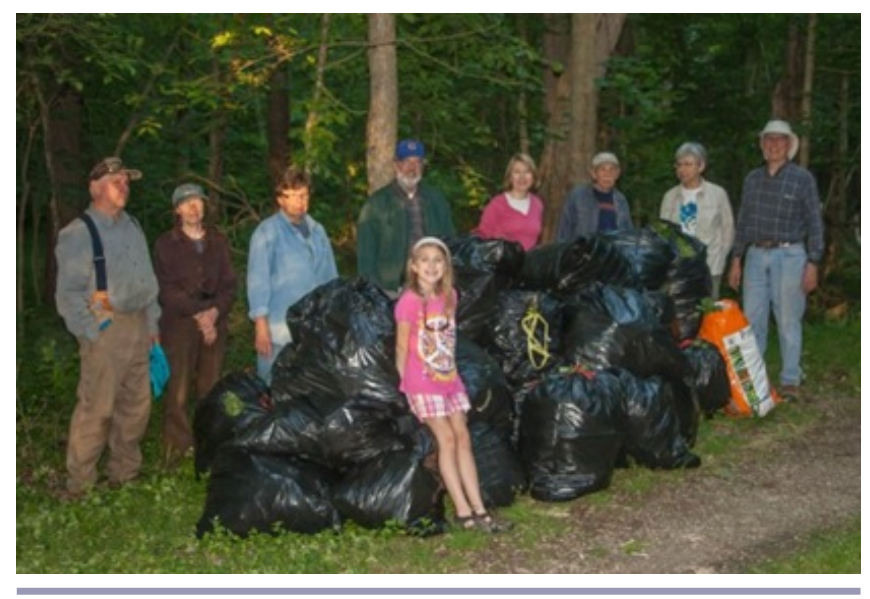

\section{A MODEL FOR WORK AT THE INTERFACE OF SCIENCE AND PRACTICE IN THE DOMAIN OF ECOLOGY AND SOCIETY}

Few organizations work squarely in the domain of ecology and society, and fewer still bring transdisciplinary science about ecology and society into practice. Rather than aiming to conserve individual species or ecosystems, TSN pursues environmental conservation through social capacity building. This is what makes TSN's model scalable and transferable. The steps necessary to 
form a cluster within a small watershed are the same as for a large watershed. The cycle of practitioners and researchers engaging with each other in the problem definition, design, study, and interpretation phases of stewardship learning is crucial even at the basin scale. Moreover, these steps make sense for stewardship planning in any geographic area where human communities live and interact with each other and the natural world. Of course, many people are motivated to steward land and water because of their emotional connection to a place. However, once empowered, people can extend their stewardship motivations to other geographic areas. TSN's use of networking practices and technologies makes it possible for the cycle of stewardship learning to occur across multiple spatial and temporal scales.

The New England offshoot of TSN is an example of the model's scalability and transferability. With funding from the U.S. Forest Service, TSN collaborated with the University of New Hampshire Cooperative Extension to launch The Stewardship Network: New England. Similar to TSN in the Great Lakes, this regional initiative is working to increase and support volunteer engagement in natural areas stewardship, and to launch and support clusters in New Hampshire and surrounding states. The New England network emerged after a stakeholder meeting that gathered participants to explore how working collaboratively could further their missions. This community of stakeholders now consists of 70 organizations and 1300 individuals actively planning and conducting stewardship activities. The emergence of the New England network demonstrates how TSN's model is not only scalable from watersheds to regions, but also transferable to geographic areas outside Michigan and the Lake States.

The staff of TSN also reflects the scalability and transferability of the organization's model. When TSN decided to hire a coordinator to support the work of the Grand-Raisin Cluster, one of the most competitive applicants was Spencer Kellum, son of Bob Kellum, an early leader in the Grand-Raisin Cluster and co-founder of ICP. Spencer Kellum had grown up helping his father with stewardship work in the Grand-Raisin watersheds and on his family's $1.2-\mathrm{km}^{2}$ property along Iron Creek. He worked as part of the ICP crew during the summers, conducting prescribed burns and other restoration activities. After going away to college and then graduate school, he decided he wanted to apply the natural resource management and planning expertise he had acquired to the practice of stewardship in the place where he grew up. Now Conservation Strategy Coordinator at TSN, Kellum is in many ways a product of TSN's stewardship learning process. "I just kind of grew up with The Stewardship Network. I just thought this is the way everyone did it," Kellum says of TSN's model. As a local cluster member, he helped build tacit knowledge about stewardship. As a professional, he helps convert tacit knowledge about stewardship into explicit knowledge and combines these two types of knowledge. Working as an expertpractitioner alongside his family and neighbors, he helps internalize explicit knowledge about stewardship back into tacit knowledge through practice. Through the role Kellum plays in stewardship learning, he helps transfer TSN's stewardship model to other areas beyond the Grand-Raisin Cluster and helps scale up the model that contributed to the success of the Grand-Raisin Cluster and ICP to larger areas.

One of the things that makes TSN different from other organizations is that is that it asks communities the critical question: What do you need to increase capacity to care for land and water? TSN helps local communities determine the geographic boundaries and programmatic priorities for stewardship that make sense for their local social-ecological system, and demarcate the planning area accordingly. As eco-civic regions, TSN's clusters maximize the area that residents consider part of their community while also retaining a high degree of ecological and social homogeneity, which leads to greater commitment to civic engagement in resource management (Brunckhorst et al. 2006). Grounded in transdisciplinary scientific knowledge co-generated by researchers and practitioners, the result is high-impact, transformative stewardship that engenders social and ecological change.

Responses to this article can be read online at: http://www.ecologyandsociety.org/issues/responses. $\mathrm{php} / 8121$

\section{Acknowledgments:}

The author acknowledges Dr. Doug Landis and Dr. Robert Grese for reviewing this paper.

\section{LITERATURE CITED}

Argyris, C., and D. A. Schon. 1978. Organizational learning: a theory of action perspective. Addison Wesley, Cambridge, UK.

Brunckhorst, D., P. Coop, and I. Reeve. 2006. 'Eco-civic' optimisation: a nested framework for planning and managing landscapes. Landscape and Urban Planning 75(3-4):265-281. http://dx.doi.org/10.1016/j.landurbplan.2005.04.001

Garvin, D. A. 1993. Building a learning organization. Harvard Business Review 71(4):78-91.

Guston, D. H. 2001. Boundary organizations in environmental policy and science: an introduction. Science, Technology, and Human Values 26(4):399-408. http://dx.doi.org/10.1177/0162243$\underline{90102600401}$

Holling, C. S. 1978. Adaptive environmental assessment and management. Wiley, London, UK.

McCance, E. 2011. Networking to conserve biodiversity: the case of Chicago Wilderness. Journal of Natural Resources Policy Research 3(3):237-250. http://dx.doi.org/10.1080/19390459.2011.591762

Moskovits, D. K., C. Fialkowski, G. M. Mueller, T. A. Sullivan, J. Rogner, and E. McCance. 2004. Chicago Wilderness: a new force in urban conservation. Annals of the New York Academy of Sciences 1023:215-236. http://dx.doi.org/10.1196/annals.1319.011

Nonaka, I. 1994. A dynamic theory of organizational knowledge creation. Organization Science 5(1):14-37. http://dx.doi. org/10.1287/orsc. 5.1 .14

O’Mahony, S., and B. A. Bechky. 2008. Boundary organizations: enabling collaboration among unexpected allies. Administrative Science Quarterly 53(3):422-459. http://dx.doi.org/10.2189/ asqu. 53.3.422 
Rogers, E. M. 1983. Diffusion of innovations. Free Press, New York, New York, USA.

Roux, D. J., K. H. Rogers, H. C. Biggs, P. J. Ashton, and A. Sergeant. 2006. Bridging the science-management divide: moving from unidirectional knowledge transfer to knowledge interfacing and sharing. Ecology and Society 11(1):4. [online] URL: http:// www.ecologyandsociety.org/vol11/iss1/art4/

Walters, C. J. 1986. Adaptive management of renewable resources. Macmillan, New York, New York, USA.

Walters, C. J. 1998. Improving links between ecosystem scientists and managers. Pages 272-286 in M. L. Pace and P. M. Groffman, editors. Successes, limitations, and frontiers in ecosystem science. Springer, New York, New York, USA. http://dx.doi. org/10.1007/978-1-4612-1724-4 11 